\title{
Contribuição ao estudo das atividades antifúngica e elicitora de fitoalexinas em sorgo e soja por eucalipto (Eucalyptus citriodora)*
}

\author{
Solange Maria Bonaldo ${ }^{1,3}$; Kátia Regina Freitas Schwan-Estrada ${ }^{1,4}$; José Renato Stangarlin²,4, Maria Eugênia Silva \\ Cruz $^{1}$; Ana Cristina Grade Fiori-tutida ${ }^{1}$
}

\begin{abstract}
${ }^{1}$ Departamento de Agronomia, Universidade Estadual de Maringá (UEM), Av. Colombo 5790, Cep 87.020-900, Maringá-PR, Brasil, email: schwan@wnet.com.br. ${ }^{2}$ Centro de Ciências Agrárias, Universidade Estadual do Oeste do Paraná (UNIOESTE), Rua Pernambuco 1777, Caixa Postal 1008, CEP 85960-000, Marechal Cândido Rondon. ${ }^{3}$ Bolsista PIBIC-CNPq. ${ }^{4}$ Bolsistas de Produtividade em Pesquisa do CNPq. *Trabalho de Iniciação Científica do primeiro autor. Autor para correspondência: Kátia R.F. Schwan-Estrada.

Data da chegada: 30/01/2006. Aceito para publicação em: 16/01/2007.
\end{abstract}

1317

\section{RESUMO}

Bonaldo, S.M.; Schwan-Estrada, K.R.F.; Stangarlin, J. R.; Cruz, M.E.S.; Fiori-Tutida, A.C.G. Contribuição ao estudo das atividades antifúngica e elicitora de fitoalexinas em sorgo e soja por eucalipto (Eucalyptus citriodora). Summa Phytopathologica, v.33, n.4, p.383-387, 2007.

\begin{abstract}
Compostos secundários presentes em plantas medicinais desempenham funções importantes em interações planta-patógeno, por ação antimicrobiana direta ou induzindo a síntese de mecanismos de defesa em outras plantas. Para verificar o efeito fungitóxico do eucalipto sobre o crescimento micelial de Rhizoctonia solani, Sclerotium rolfsii, Phytophthora sp, Alternaria alternata e Colletotrichum sublineolum, o extrato bruto (EB) foi incorporado ao BDA e o óleo essencial (OE) foi distribuído na superfície do meio com alça de Drigalski. A germinação de esporos de C. sublineolum também foi avaliada na presença de diferentes alíquotas de OE. Para verificar a indução de fitoalexinas, mesocótilos de sorgo foram aspergidos com EB a $20 \%$ ou então, mergulhados em suspensões do OE. Para a indução de gliceolina, $20 \mu \mathrm{L}$ do EB foram colocados em cotilédones de soja. A presença de
\end{abstract}

compostos fungitóxicos no $\mathrm{OE}$ e EB através da cromatografia de camada delgada também foi avaliada. Os resultados evidenciaram inibição do crescimento micelial dos fungos para concentrações do EB acima de $20 \%$. Todas as alíquotas do óleo inibiram o crescimento micelial dos fungos testados, com exceção de $R$. solani cuja inibição ocorreu para alíquotas acima de $20 \mu \mathrm{L}$. Houve inibição de $100 \%$ na germinação dos conídios para todas as alíquotas do OE testadas na primeira metodologia, porém, na segunda metodologia o $\mathrm{OE}$ não promoveu inibição da germinação de esporos. Entretanto, foram observadas alterações na morfologia dos tubos germinativos e inibição da formação de apressórios. Observou-se a presença de apenas uma fração fungitóxica no OE, e o EB não apresentou frações fungitóxicas. Houve a produção de fitoalexinas apenas em mesocótilos de sorgo tratados com o EB.

Palavras-chave adicionais: deoxiantocianidinas, gliceolina, compostos secundários, planta medicinal.

\section{ABSTRACT}

Bonaldo, S.M.; Schwan-Estrada, K.R.F.; Stangarlin, J. R.; Cruz, M.E.S.; Fiori-Tutida, A.C.G. Contribution for the study of antifungal and phytoalexins elicitors in sorghum and soybean activities by eucalyptus (Eucalyptus citriodora). Summa Phytopathologica, v.33, n.4, p.383-387, 2007.

Secondary compounds found in medicinal plants play important role in plant-pathogen interactions by having direct antimicrobian effect on them or inducing the defense mechanisms on defense of other plants. To verify the fungi toxic effect of the eucalyptus on the micelial growth of Rhizoctonia solani, Sclerotium rolfsii, Phytophthora sp, Alternaria alternata and Colletotrichum sublineolum, the crude extract (CE) was incorporate to PDA and the essential oil (EO) and distributed in the surface of the middle with Drigalski loop. Germination of spores of C. sublineolum was also evaluated in the presence of different brackets of EO using two methodologies. In order to verify the induction phytoalexins sorghum mesocotyls were asperged with $\mathrm{CE}$ to $20 \%$ or then dived in suspensions of EO. For the gliceolin induction, $20 \mu \mathrm{L}$ of $\mathrm{CE}$ were put in cotyledons soybean. The presence of fungitoxic compounds in EO and $\mathrm{CE}$ through the thin layer chromatography was also evaluated. The results evidenced inhibition of the fungus micelial growth for concentrations of CE above $20 \%$. All of the aliquots of the oil inhibited micelial growth micelial fungi, except for $R$. solani whose inhibition happened for aliquots above $20 \mu \mathrm{L}$. There was inhibition of $100 \%$ in conidia germination for all of the aliquots of EO tested in the first methodology. However, in the second methodology EO did not promote inhibition of conidia germination. It was observed the presence of one fraction fungitoxic in EO, and $\mathrm{CE}$ did not present fungitoxic fractions. There was the phytoalexins production just in sorghum mesocotyls treated with CE.

Additional Keywords: deoxyanthocyanidin, gliceollin, secondary compounds, medicinal plant. 
Alguns dos problemas associados à utilização de agrotóxicos para o controle de doenças em plantas incluem freqüentes falhas no controle, devido à aquisição de resistência por parte dos fitopatógenos, contaminação ambiental e danos à saúde dos seres humanos. Em função destas preocupações e das pressões exercidas pela sociedade, houve um incentivo para que pesquisadores e produtores buscassem novos caminhos para o controle de doenças nas mais diferentes culturas (6, 7). Neste contexto, o uso de plantas medicinais para o controle de fitopatógenos tem sido demonstrado em diversos trabalhos.

Segundo Bankole \& Joda (1) o óleo essencial e o pó de folhas de capim limão (Cymbopogon citratus Stapf) reduzem a extensão da deterioração em sementes de melão inoculadas anteriormente com Aspergillus flavus, A. niger, A. tamarii e Penicillium citrinum. Os autores verificaram, também, que o óleo essencial de capim limão nas concentrações de 0,1 e $0,25 \%$ (v/m) proporcionou significativa redução da produção de aflatoxina em sementes descascadas e inoculadas com A. flavus. Altas concentrações do óleo essencial $(0,5$ e $1,0 \mathrm{v} / \mathrm{m})$ preveniram completamente a produção de aflatoxina nas sementes.

A atividade antifúngica de diferentes concentrações do extrato etanólico de espinheira-santa (Burch. ex London) Planch sobre o crescimento micelial de Colletotrichum acutatum, Fusarium oxysporum e Cylindrocladium spathulatum foi avaliada por Cunico et al. (4). Os resultados mostraram que o extrato inibiu em mais de $10 \%$ o crescimento micelial de $F$. oxysporum, nas três concentrações avaliadas $(0,2 ; 0,4$ e $0,6 \mathrm{mg} / \mathrm{mL}$ ), estimulou o crescimento micelial de C. acutatum em mais de $30 \%$ na concentração de $0,2 \mathrm{mg} / \mathrm{mL}$ e algumas de suas frações inibiram o desenvolvimento de $C$. spathulatum.

Folhas secas de Lippia alba em contato com suspensão de esporos de Colletotrichum gloeosporioides, promoveram o aumento do comprimento e da largura dos tubos germinativos formados, a inibição da formação de apressórios e substâncias solúveis em etanol exerceram efeito fungistático in vitro (8).

Bonaldo et al. (3) verificaram o potencial de Eucalyptus citriodora no controle alternativo de antracnose em pepino utilizando extrato aquoso (EA) desta essência florestal, autoclavado ou não autoclavado, em diferentes concentrações e observaram que houve inibição total na germinação de esporos e formação de apressórios de Colletotrichum lagenarium em concentrações de $20 \%$ e $1 \%$ do EA autoclavado, respectivamente. Para o extrato não autoclavado houve $75 \%$ de inibição da germinação de esporos em $25 \%$ do EA e inibição total da formação de apressórios em $15 \%$ do EA.

Assim, verifica-se que o uso de E. citriodora bem como de outras plantas medicinais, no controle de fitopatógenos presentes no solo ou na parte aérea de plantas, apresenta um futuro promissor. Em função do exposto, o presente trabalho foi desenvolvido com os objetivos de avaliar: i) o efeito do óleo essencial e do extrato aquoso (EA) de $E$. citriodora no crescimento micelial de alguns fungos fitopatogênicos, bem como na formação de apressórios e germinação de conídios por $C$. sublineolum; ii) verificar o efeito do EA na indução de fitoalexinas em sorgo e soja e iii) detectar, através de cromatografia de camada delgada, os compostos fungitóxicos presentes tanto no óleo essencial quanto no extrato bruto aquoso.

\section{MATERIAL E MÉTODOS}

\section{Fungos fitopatogênicos}

O efeito do óleo essencial e do extrato bruto aquoso de E. citriodora foi verificado sobre o crescimento micelial de Rhizoctonia solani, Sclerotium rolfsii, Phytophthora sp., C. sublineolum e Alternaria alternata.

\section{Crescimento micelial in vitro}

$\mathrm{Na}$ obtenção do extrato bruto (EB) folhas frescas da planta medicinal eucalipto (E. citriodora) foram trituradas em água destilada por $3 \mathrm{~min}$., em liquidificador. $\mathrm{O}$ homogenato resultante foi filtrado em gaze e em papel de filtro Whatman $n^{\circ} 1$, obtendo-se o extrato bruto aquoso, o qual foi incorporado ao BDA de modo a se obter concentrações de $5,10,15,20,25$ e $50 \%$ e autoclavados a $120^{\circ} \mathrm{C} 1$ atm por $20 \mathrm{~min}$. Após a solidificação do meio, um disco de $8 \mathrm{~mm}$ de diâmetro contendo micélio dos isolados dos fitopatógenos, com 15 dias de idade, foi repicado para o centro das placas, as quais foram vedadas e mantidas a $28^{\circ} \mathrm{C}$ e no escuro. Foram utilizadas cinco repetições por tratamento. $\mathrm{O}$ tratamento controle continha apenas o meio BDA. A avaliação foi realizada através da medição diária do diâmetro das colônias (média de duas medidas diametralmente opostas), 24 horas após a instalação do experimento e perdurou até o momento em que as colônias fúngicas no tratamento controle cobriram $2 / 3$ da superfície do meio de cultura. Ensaio semelhante foi realizado com óleo essencial de E. citriodora obtido por arraste a vapor, a partir de folhas secas ao ar. Após esterilização em filtro $(0,2 \mathrm{~mm})$ descartável para seringa, alíquotas de 20,40,100, 500 e 1000 mL do óleo essencial foram colocadas no centro de placas de Petri contendo cerca de $20 \mathrm{~mL}$ de BDA e distribuídas sobre a superfície do meio com alça de Drigalsky.

\section{Germinação de conídios e formação de apressórios por Colletotrichum sublineolum}

Na germinação de conídios por C. sublineolum foram utilizadas duas metodologias. Na primeira, lâminas de microscopia foram cobertas com uma fina camada agar-água e sobre estas foram colocadas alíquotas de 5, 10,20, 40 e $60 \mu 1$ do óleo essencial e $100 \mu 1$ de uma suspensão de esporos $\left(2 \times 10^{4}\right.$ conídos $\left./ \mathrm{mL}\right)$ de C. sublineolum, permanecendo em câmara úmida por 22 horas, sob luz constante e $24{ }^{\circ} \mathrm{C}$. Após este período, com auxílio de microscópio óptico, foi realizada a contagem de conídios germinados e apressórios formados. Na segunda metodologia empregada, suspensões do óleo essencial dissolvidas em água destilada mais Tween (20\%) nas concentrações de $10^{-2}, 10^{-4}, 10^{-6}, 10^{-8}$ e $10^{-10}$ foram colocadas sobre a superfície de placas de Petri contendo agar-água (2\%). Como tratamentos controles foram utilizadas água destilada e água destilada+Tween. Em seguida, adicionou-se $100 \mu \mathrm{L}$ da suspensão de esporos ( $1 \times 10^{5}$ esporos $\left./ \mathrm{mL}\right)$ de C. sublineolum que foi distribuída sobre a superfície do BDA com auxílio de alça de Drigalsky. As placas de Petri foram então incubadas sob luz constante, a $27^{\circ} \mathrm{C}$, por um período de 20 horas. Após este período, com auxílio de microscópio óptico, foi realizada a contagem de conídios germinados.

\section{Cromatografia de camada delgada}

Alíquotas de $100 \mu \mathrm{L}$ do óleo essencial e do EB de E. citriodora foram utilizadas para a cromatografia de camada delgada em placas de sílica-gel 60 com indicador fluorescente $(254 \mathrm{~nm})$, pré-lavadas com clorofórmio/metanol (1:1, v/v). Após a colocação das amostras sobre as placas e secagem sob fluxo de ar, foi realizada a separação dos compostos usando butanol/ácido acético/água (6:1:2, v/v/v) como sistema de solvente. Os compostos foram visualizados sob luzes visível e ultravioleta longo (365 nm) e curto $(254 \mathrm{~nm})$. A seguir, as placas de sílica-gel secas contendo as bandas individuais foram aspergidas com suspensão de esporos de C. sublineolum ( $1 \times 10^{5}$ conídios $/ \mathrm{mL}$ em meio líquido Czapeck) e mantidas sob umidade relativa de $100 \%$ a $25^{\circ} \mathrm{C}$ e luz. Após 48 horas, as placas foram observadas para a presença de zonas de inibição de crescimento micelial ao redor das bandas individuais. 


\section{Produção de fitoalexinas em sorgo e soja}

Para a síntese de fitoalexinas em sorgo, mesocótilos de sorgo, estiolados, foram aspergidos com EB de E. citriodora e com suspensão de células de Saccharomyces cerevisiae, C. sublineolum ou expostas à UV $(265 \mathrm{~nm})$ por uma hora, como tratamentos controle. Após 3 dias, 3 mesocótilos foram cortados $(0,5 \mathrm{~mm})$ e colocados em $2 \mathrm{ml}$ de metanol acidificado por 60 horas a $4^{\circ} \mathrm{C}$ para a extração dos pigmentos. A leitura de absorbância foi a $480 \mathrm{~nm}$.

Para verificar a síntese de fitoalexinas pelo óleo essencial de $E$. citriodora, 3 mesocótilos de sorgo foram colocados em tubos de ensaio contendo os tratamentos com óleo essencial a $10^{-2}, 10^{-4}, 10^{-6}, 10^{-8}$ e $10^{-}$ 10; e os tratamentos controle: água destilada e água destilada+Tween. Os tubos de ensaio foram colocados sob luz constante por aproximadamente 60 horas, a uma temperatura constante de $24 \mathrm{C}$. Após 3 dias, 3 mesocótilos foram cortados $(0,5 \mathrm{~mm})$ e colocados em $2 \mathrm{ml}$ de metanol acidificado por 60 horas a $4^{\circ} \mathrm{C}$ para a extração dos pigmentos. A leitura de absorbância foi a $480 \mathrm{~nm}$.

Para a síntese de gliceolina, cotilédones de soja foram retirados das plântulas, lavados com água destilada e seccionados na superfície inferior. Seis cotilédones foram colocados em placas de Petri com papel de filtro umedecido. Alíquotas de $20 \mu \mathrm{l}$ de EA de E. citriodora, de $S$. cerevisiae ou de $C$. sublineolum foram aplicados sobre a lesão. Como controle, foi utilizada água destilada esterilizada. Após 20 horas, os cotilédones foram transferidos para tubos com $10 \mathrm{ml}$ de $\mathrm{H}_{2} \mathrm{O}$ destilada esterilizada e agitados por uma hora. A leitura de absorbância foi a $285 \mathrm{~nm}$.

\section{RESULTADOS E DISCUSSÃO}

\section{Crescimento micelial in vitro}

O efeito inibitório de diferentes concentrações do EB de $E$. citriodora sobre os fungos $R$. solani, S. rolfsii, C. sublineolum, Phytophthora sp e A. alternata está representado na Figura 1. Observase que a partir de $20 \%$ da concentração do extrato bruto, todos os fungos apresentaram inibição do crescimento micelial, e que Phytophthora sp. e C. sublineolum apresentaram a maior inibição do crescimento micelial, seguidos de $S$. rolfsii, $R$. solani e A. alternata.

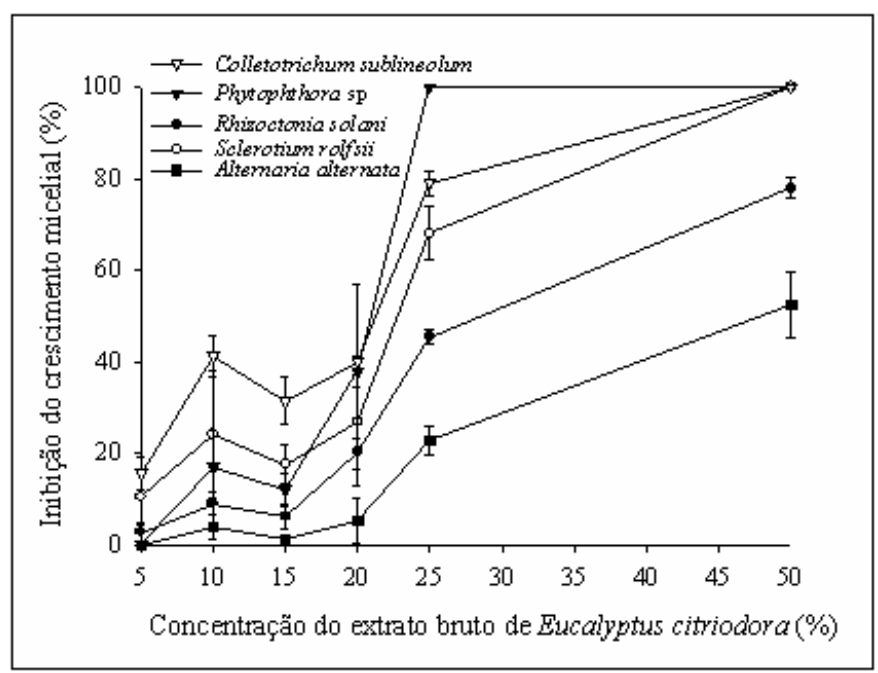

Figura 1. Inibição do crescimento micelial de fitopatógenos na presença de diferentes concentrações de extrato bruto de Eucalyptus citriodora. As barras representam o desvio padrão da média de 5 repetições.
Já o óleo essencial, nas alíquotas de 40, 100, 500 e $1000 \mu \mathrm{L}$ promoveu $100 \%$ de inibição do crescimento micelial dos fungos testados. Na alíquota de $20 \mu \mathrm{L}$ houve $100 \%$ de inibição do crescimento micelial para $S$. rolfsii, Phytophthora sp, A. alternata e C. sublineolum e de $90 \%$ para $R$. solani. Os resultados obtidos concordam com os de Fiori et al. (5) que trabalhando com os óleos essenciais de E. citriodora, C. citratus e A. conizoides, verificaram que os mesmos inibiram o crescimento micelial de Didymella bryoniae em 100\% nas alíquotas testadas $(20,40,60,100,200,500$ e $1000 \mu \mathrm{L})$, e que o óleo essencial de $A$. millefolium nas alíquotas de $20,40,60,100$ e $200 \mu \mathrm{L}$ promoveu inibição do crescimento micelial em 35,02\%, 50,46\%, 57,02\%, 74,53\% e $89,29 \%$ respectivamente e nas alíquotas de 500 e $1000 \mu \mathrm{L}$ ocorreu $100 \%$ de inibição. Barros et al (2) avaliando o efeito do extrato de bulbo de alho no crescimento micelial de Curvularia brachyspora, $C$. pallescens, $A$. alternata e $A$. longipes verificaram que todos os fungos foram sensíveis à concentração de $250 \mathrm{ppm}$, havendo redução significativa no diâmetro das colônias com o aumento das concentrações do extrato de alho.

\section{Germinação de conídios e formação de apressórios por $C$. sublineolum}

Nos resultados da primeira metodologia utilizada para a avaliação da germinação de conídios de C. sublineolum nas alíquotas testadas de óleo essencial de E. citriodora, observou-se que substância (s) presente(s) no óleo essencial inibe (m) em 100\% a germinação e formação de apressórios por C. sublineolum em todas as alíquotas testadas.

Na Figura 2, são ilustrados os resultados da segunda metodologia utilizada para a avaliação da germinação de conídios e formação de apressórios de C. sublineolum. Em todas as suspensões do óleo essencial houve germinação de esporos, porém, sem formação de apressórios. Alterações na morfologia dos tubos germinativos foram observadas. Na concentração de $10^{-2}$ do óleo essencial, os tubos germinativos eram pequenos, praticamente do mesmo tamanho dos esporos; na concentração do óleo essencial de $10^{-4}$ os tubos germinativos eram pequenos (mesmo tamanho ou menores que o esporo), ou então extremamente longos. Tubos menores que os esporos foram observados na concentração de $10^{-6}$ do óleo essencial.

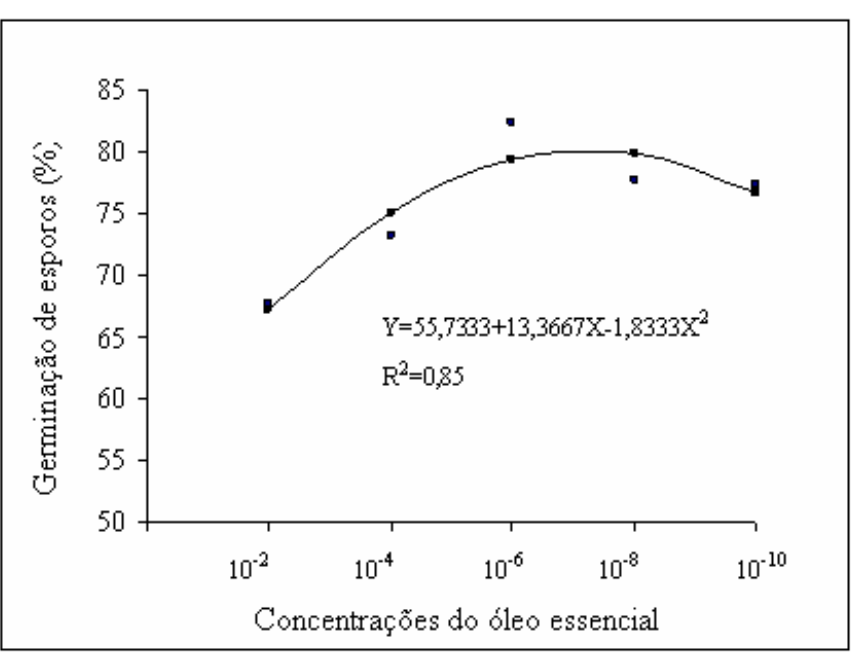

Figura 2. Germinação de esporos de Colletotrichum sublineolum em diferentes concentrações de óleo essencial de Eucalyptus citriodora. Controles: Água: $80 \pm 12,16$. Água + Tween: $83 \pm 2,00$. 
Os resultados obtidos foram semelhantes ao obtidos por Santos et al. (8) que verificaram que a formação de apressórios por conídios de $C$. gloeosporiodes foi afetada em todos os tratamentos contendo discos de folhas secas de Lippia alba e que afetaram também o tamanho (comprimento e largura) dos tubos germinativos, que apresentaram-se mais longos e mais largos. Stangarlin et al. (11) observaram que ocorreu estímulo da germinação de esporos e redução de 14 a 34 \% na formação de apressórios de C. graminicola (Ces.) Wilson, em concentrações do extrato bruto de $E$. citriodora, não autoclavado acima de $10 \%$.

Bonaldo et al. (3) relataram inibição total na germinação de esporos e formação de apressórios por C. lagenarium em concentrações de $20 \%$ e $1 \%$ de extrato aquoso de E. citriodora autoclavado. Também observaram que extrato aquoso não autoclavado promoveu $75 \%$ de inibição da germinação de esporos em $25 \%$ do extrato e inibição total da formação de apressórios em 15\%.
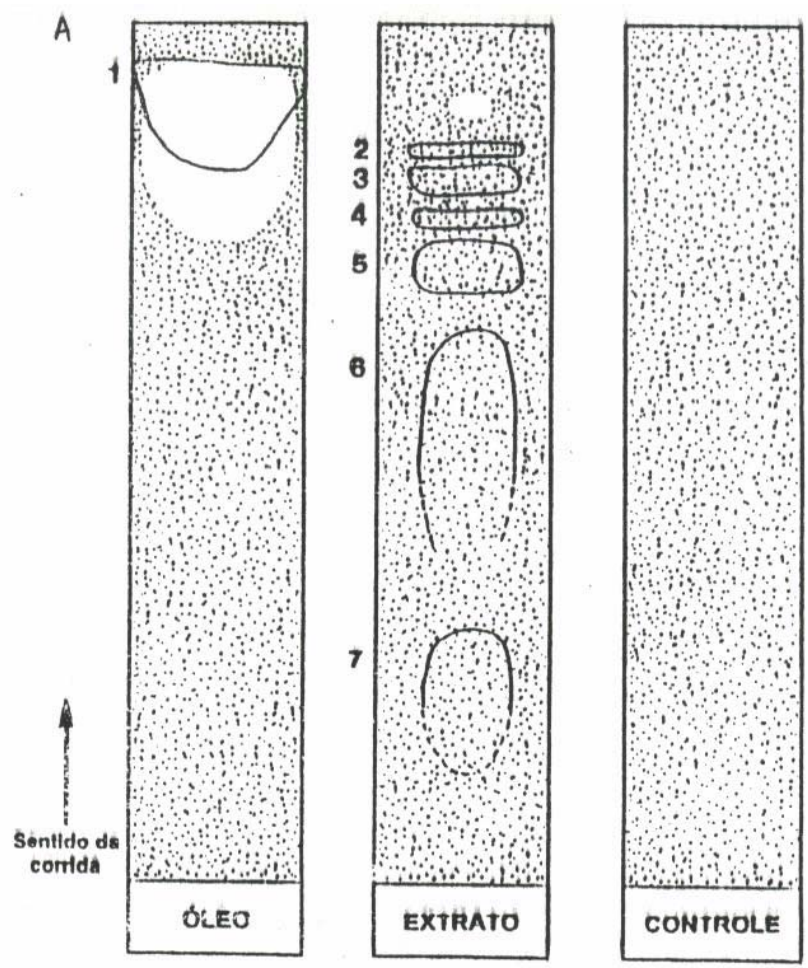

B

\begin{tabular}{ccccc}
\hline & \multicolumn{4}{c}{ Aspecto sob luz } \\
\hline \multirow{2}{*}{ Bandas } & Visível & \multicolumn{2}{c}{ U.V. } & MR \\
\cline { 3 - 4 } & & $\mathbf{3 6 5} \mathbf{~ n m}$ & $\mathbf{2 5 4} \mathbf{~ n m}$ \\
\hline 1 & - & - & marrom escuro & 0,94 \\
\hline 2 & amarelo claro & - & marrom claro & 0,86 \\
\hline 3 & amarelo escuro & marrom escuro & marrom escuro & 0,83 \\
\hline 4 & amarelo claro & - & marrom claro & 0,78 \\
\hline 5 & - & marrom escuro & - & 0,75 \\
\hline 6 & - & marrom escuro & marrom escuro & 0,64 \\
\hline 7 & marrom claro & marrom escuro & marrom escuro & 0,29 \\
\hline & & & &
\end{tabular}

Figura 3. (A) Bioensaio para caracterização de frações fungitóxicas em óleo essencial e extrato bruto de Eucalyptus citriodora. A área clara ao redor das bandas indica inibição do crescimento micelial de Colletotrichum sublineolum. (B) Características das frações obtidas por cromatografia em camada delgada. MR: mobilidade relativa.

\section{Cromatografia em camada delgada}

No bioensaio para a detecção de compostos fungitóxicos presentes no óleo essencial e EB, foi possível detectar a presença de frações nas quais houve inibição do desenvolvimento de $C$. sublineolum (Figura 3). A banda 1 na alíquota de óleo essencial visualizada sob luz ultravioleta $(254 \mathrm{~nm})$ e uma pequena região na alíquota de extrato bruto, não detectada sob os comprimentos de onda observados, exibiram efeito fungitóxico ao fungo utilizado no experimento.

Silva et al. (10) observaram que frações aceto-etanólica (raízes) e clorofórmica (caule) de Esenbechya grandiflora, uma Rutaceae com referência antimicrobiana, mostraram uma ED 50 $>600$ ppm com relação ao crescimento micelial e germinação dos conídios de Botryodiplodia theobromae e que a análise de cromatogramas permitiu o isolamento de pelo menos duas substâncias fungitóxicas.

\section{Produção de fitoalexinas em sorgo e soja}

Observou-se que o EB induziu o acúmulo de deoxiantocianidinas em mesocótilos de sorgo (Figura 4). As maiores produções das fitoalexinas deoxiantocianidinas foram promovidas pelo patógeno C. sublineolum, seguida da levedura S. cerevisiae. Porém, em cotilédones de soja, o EB não induziu o acúmulo de gliceolina, onde a maior indução foi proporcionada por $C$. sublineolum e nos tratamentos com UV e S. cerevisiae (Figura 5). Schwan-Estrada et al. (9) trabalhando com extratos de orégano, cardo santo, hortelã, alecrim, mentrasto, babosa, manjerona, erva cidreira, cânfora, pitanga, goiabeira, romã, alfavaca, mil-folhas e poejo, verificaram que estes extratos promoviam a síntese de fitoalexinas deoxiantocianidinas em sorgo e da fitoalexina gliceolina em soja. Os autores também observaram que os extratos de romã, erva cidreira, manjerona, babosa e orégano foram mais efetivos na indução de gliceolina, e que os extratos de pitanga, cânfora, poejo, romã e cardo santo foram mais efetivos na indução de deoxiantocianidinas.

Os resultados da síntese de fitoalexinas pelo óleo essencial de E. citriodora estão ilustrados na Figura 6. Observou-se, que o óleo essencial, nas concentrações testadas, não promove a

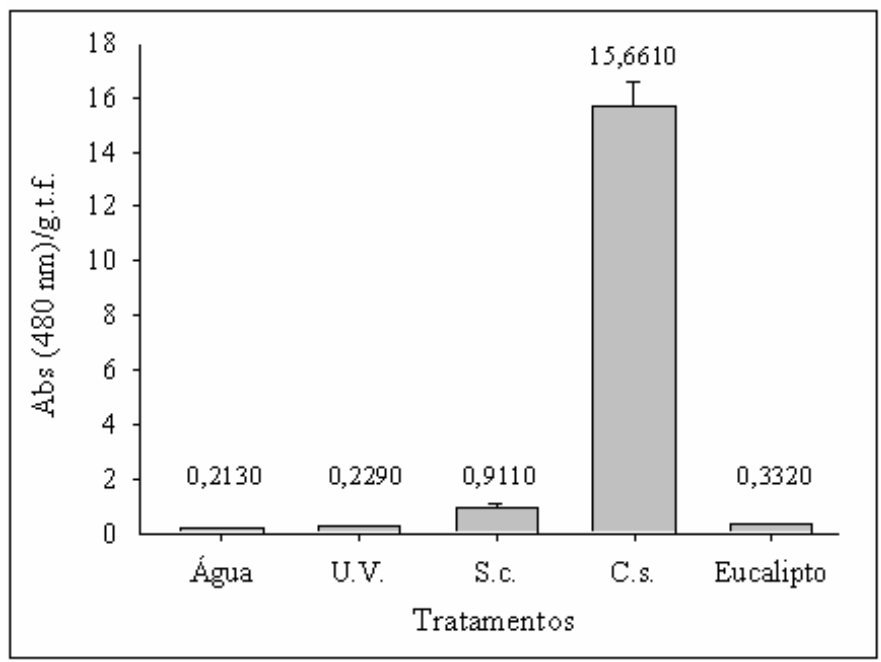

Figura 4. Acúmulo de um complexo de pigmentos em mesocótilos de sorgo tratados com Água destilada (controle); U.V.: Ultravioleta; S.c.: Saccharomyces cerevisiae; C.s.: Colletotrichum sublineolum e extrato bruto de Eucalyptus citriodora. As barras representam o desvio padrão da média de 5 repetições. 


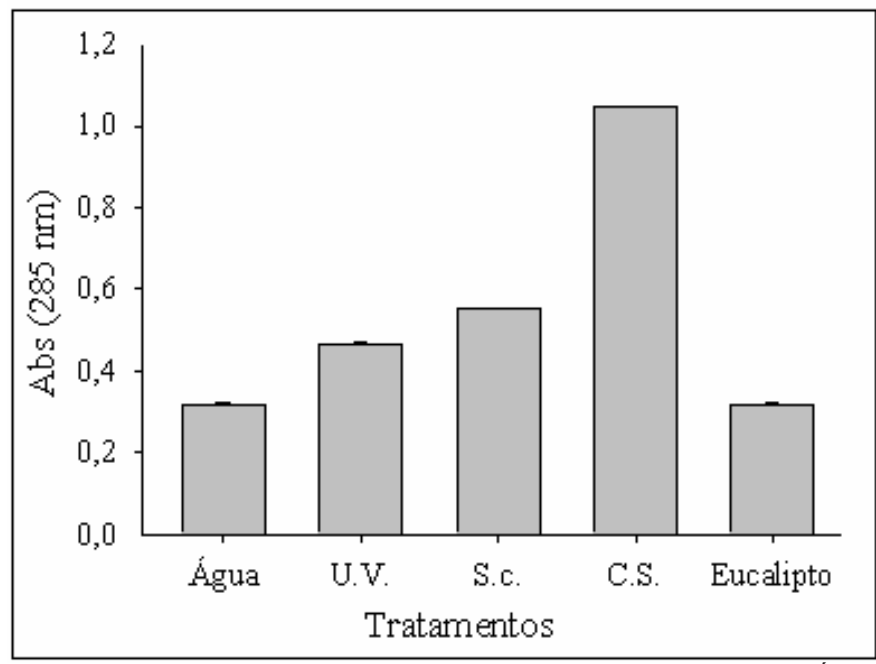

Figura 5. Acúmulo de gliceolina em cotilédones de soja tratados com Água destilada (controle); U.V.: Ultravioleta; S.c.: Saccharomyces cerevisiae; C.s.: Colletotrichum sublineolum e extrato bruto de Eucalyptus citriodora. As barras representam o desvio padrão da média de 3 repetições.

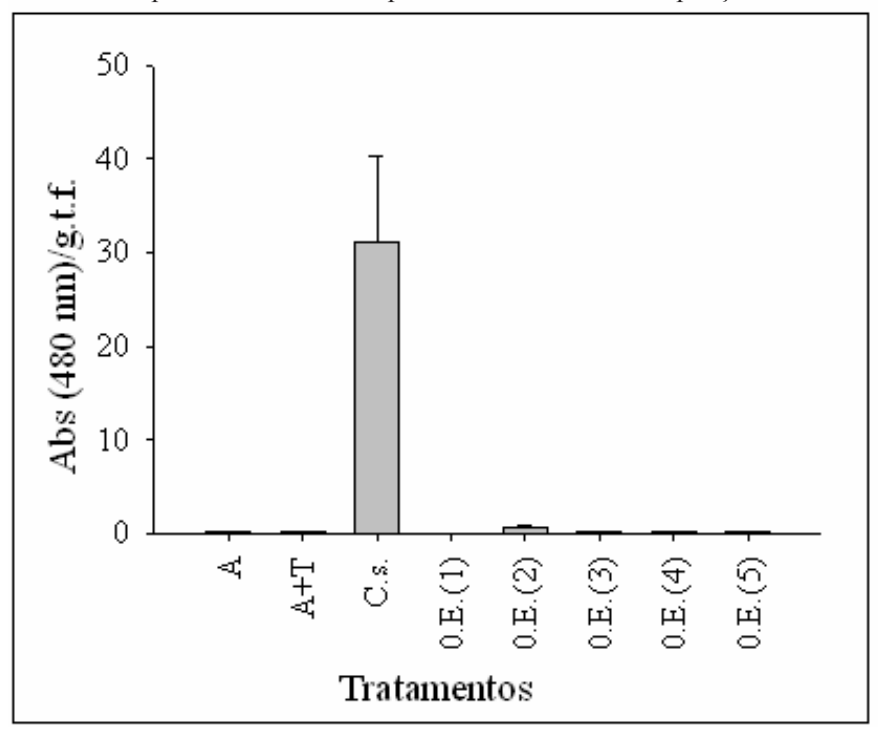

Figura 6. Acúmulo de um complexo de pigmentos em mesocótilos de sorgo tratados com A: água destilada; $\mathrm{A}+\mathrm{T}$ : água destilada + Tween; C.s.: Colletotrichum sublineolum; O.E.(1): óleo essencial $10^{-2}$; O.E.(2): óleo essencial $10^{-4}$; O.E.(3): óleo essencial $10^{-6}$; O.E.(4): óleo essencial $10^{-8}$; O.E.(5): óleo essencial $10^{-10}$. As barras representam o desvio padrão da média de 3 repetições.

síntese de fitoalexinas em sorgo. Houve maior acúmulo de fitoalexinas em mesocótilos tratados com C. sublineolum. Provavelmente, a tentativa de nortear o efeito fitotóxico do óleo essencial sobre os mesocótilos de sorgo, através da diluição do mesmo, tenha reduzido a atividade elicitora. Assim, trabalhos futuros devem ser realizados avaliando-se novas diluições e/ou metodologias para evitar o efeito fitotóxico do óleo essencial sobre estes tecidos.
O presente trabalhou evidenciou o potencial de E. citriodora na proteção de plantas, seja pelo controle direto de fitopatógenos como $S$. rolfsii, C. sublineolum e Phytophthora $\mathrm{sp}, R$. solani e A. alternata, em função do efeito no crescimento micelial, na germinação de esporos ou por atividade fungitóxica; ou pela ativação de mecanismos de defesa como fitoalexinas do deoxiantocianidinas em sorgo.

\section{REFERÊNCIAS BIBLIOGRÁFICAS}

1. Bankole, S.A.; Joda, A.O. Effect of lemon grass (Cymbopogon citratus Stapf) powder and essential oil on mould deterioration and aflatoxin contamination of melons seeds (Colocynthis citrullus L.). African Journal of Biotechnology, Nairobi, Kenya, v.3, n.1, p.52-59, 2004.

2. Barros, S.T.; Oliveira, N.T.; Maia, L.C. Efeito do extrato de alho (Album sativum) sobre o crescimento micelial e germinação de conídios de Curvularia spp e Alternaria spp. Summa Phytopathologica, Jaboticabal, v. 21, n.2, 1995. (Resumos).

3. Bonaldo, S.M.; Schwan-Estrada, K.R.F.; Stangarlin, J.; Tessmann, D.; Scapim, C.A Fungitoxidade, atividade elicitora de fitoalexinas e proteção de pepino contra Colletotrichum lagenarium, pelo extrato aquoso de Eucalyptus citriodora. Fitopatologia Brasileira, Brasília, v.29, n.02, p.128-134, 2004.

4. Cunico, M.M.; Cirio, G.M.; Miguel, O.G.; Miguel, M.D.; Montrucchio, D.P.; Auer, C.G.; Grigoletti Júnior, A. Contribuição ao estudo da atividade antifúngica de Maytenus ilicifolia Mart. ex Reiss., Celastraceae. Revista Brasileira de Farmacognosia, Maringá, v.12, n.2, p.69-73, 2002.

5. Fiori, A.C.G.; Schwan-Estrada, K.R.F.; Stangarlin, J.R.; Vida, J.B.; Scapim, C.A.; Cruz, M.E.S.; Pascholati, S.F. Antifungal activity of leaf extracts and essential oils of some medicinal plants against Didymella bryoniae. Journal Phytopathology, Berlin, v.148, p.483-487, 2000 .

6. Gullino M.L.; Kuijpers L.A.M. Social and political implications of managing plant diseases with restricted fungicides in Europe. Annual Review of Phytopathology, Palo Alto, v.32, p.559-579, 1994 .

7. Ragsdale, N.N.; Sisler H.D. Social and political implications of managing plant diseases with decreased availability of fungicides in the United States. Annual Review of Phytopathology, Palo Alto, California, v.32, p.545-557, 1994.

8. Santos, M.M.F.B.; Pascholati, S.F. Efeito de metabólitos de duas formas de Lippia alba sobre o fungo Colletotrichum gloeosporioides (Penz.), isolado Citrus sp. 1996. 105p. Dissertação (Mestrado em Fitopatologia) - Escola Superior de Agricultura Luiz de Queiroz/Universidade de São Paulo, Piracicaba.

9. Schwan-Estrada, K.R.F.; Cruz, M.E.S., Stangarlin, J.R.; Pascholati, S.F. Efeito do extrato bruto de plantas medicinais na indução de fitoalexinas em soja e sorgo. Fitopatologia Brasileira, Brasília, v.22, sup1., p.346-346, 1997. (Resumo).

10. Silva, J.B. da; Conserva, LM.; Lopez, A.M.Q. Efeito dos extratos aceto-etanólicos (raízes) e clorofórmicos (caule) de Esenbeckya grandiflora sobre Botryodiplodia theobromae. Fitopatologia Brasileira, Brasília, v. 29, supl., p.276-276, 1994. (Resumo).

11. Stangarlin, J.R., Schwan-Estrada, K.R.F.; Cruz, M.E.S.; Nozaki, M.H. Plantas medicinais e controle alternativo de fitopatógenos. Biotecnologia Ciência \& Desenvolvimento, Brasília, v.11, p. 16-21, 1999. 